\title{
Responsiveness of Muscle Protein Synthesis to Growth Hormone Administration in HIV-infected Individuals Declines with Severity of Disease
}

\author{
Margaret A. McNurlan, ${ }^{*}$ Peter J. Garlick, ${ }^{\star}$ Roy T. Steigbigel, ${ }^{\ddagger}$ Kim A. DeCristofaro, ${ }^{\ddagger}$ Robert A. Frost, ${ }^{\ddagger}$ Charles H. Lang, ${ }^{\star}$ \\ Richard W. Johnson,,$^{\S}$ Anita M. Santasier, ${ }^{\S}$ Corazon J. Cabahug, Jack Fuhrer, ${ }^{\ddagger}$ and Marie C. Gelato ${ }^{\ddagger}$ \\ ${ }^{*}$ Department of Surgery, ${ }^{\ddagger}$ Department of Medicine, ${ }^{\S}$ Department of Physical Therapy, and ${ }^{\|}$Department of Radiology, State University of \\ New York at Stony Brook, Stony Brook, New York 11794
}

\begin{abstract}
This study was undertaken to determine if human recombinant growth hormone (hrGH, $6 \mathrm{mg} / \mathrm{d}$ for $2 \mathrm{wk}$ ) would stimulate muscle protein synthesis in AIDS wasting. Healthy controls were compared with patients who were HIV+, had AIDS without weight loss, and had AIDS with $>10 \%$ weight loss. Before hrGH, rates of skeletal muscle protein synthesis, measured with $\mathrm{L}-\left[{ }^{2} \mathrm{H}_{5}\right]$ phenylalanine, were the same in controls and in all stages of disease. Rates of myofibrillar protein degradation, however, assessed from urinary excretion of 3-methyl histidine, were higher in AIDS and AIDS wasting than in HIV+ or healthy individuals. The group with weight loss had significantly higher TNF $\alpha$ levels but not higher HIV viral loads. Muscle function, as determined by isokinetic knee extension and shoulder flexion, was significantly higher in controls than all infected individuals. After $\mathrm{GH}$, rates of protein synthesis were stimulated $27 \%$ in controls, with a smaller increase (11\%) in $\mathrm{HIV}+$, and a significant depression (42\%) in AIDS with weight loss, despite fourfold elevation in insulin-like growth factor-I in all groups. There was a significant correlation of hrGHinduced changes in muscle protein synthesis with severity of disease $(P=0.002)$. The results indicate increased basal muscle protein degradation and decreased responsiveness of muscle protein synthesis to $\mathrm{GH}$ in the later stages of disease. (J. Clin. Invest. 1997. 100:2125-2132.) Key words: protein degradation $\cdot 3$-methyl histidine $\bullet$ insulin-like growth factor-I $\bullet$ muscle function
\end{abstract}

\section{Introduction}

The profound loss of body weight, or wasting, associated with HIV infection is so widespread and dramatic (1-4) that it is considered as evidence for progression of the infection to AIDS (5). This extensive loss of lean body mass $(\mathrm{LBM})^{1}$ in AIDS wasting has grave consequences and is associated not

This work was presented at the Endocrine Society Annual Meeting, 1996. Portions of this work have appeared in abstract form (1996. Clin. Nutr. (Phila). 15:5).

Address correspondence to Margaret McNurlan, Ph.D., Department of Surgery, Health Sciences Center T19, State University of New York at Stony Brook, Stony Brook, NY 11794-8191. Phone: 516444-8095; E-mail: mcnurlan@surg.som.sunysb.edu

Received for publication 14 April 1997 and accepted in revised form 22 August 1997.

J. Clin. Invest.

(C) The American Society for Clinical Investigation, Inc. 0021-9738/97/10/2125/08 \$2.00

Volume 100, Number 8, October 1997, 2125-2132

http://www.jci.org only with decreased survival $(6,7)$, but also with increased hospitalization and diminished quality of life $(8,9)$. Suttmann $(10)$ and Ott (11) have both demonstrated a strong correlation of loss of LBM with mortality in AIDS patients; a correlation that is independent of other parameters, including CD4+ T-lymphocyte counts.

Loss of LBM, or body muscle mass that forms the bulk of $\mathrm{LBM}$, is also observed in other catabolic conditions such as cancer cachexia (12) and surgical trauma (13). Moreover, this loss of body weight, unlike weight loss associated with undernutrition, is associated with metabolic dysfunction that prevents the normal adaptation to the use of body fat to spare body protein (12-15). Although lack of nutrient intake may exacerbate the loss of muscle mass, the problem is not solely one of undernutrition, and is not reversed simply by nutritional means (e.g., see reference 16).

Although the precise mechanism for the loss of body protein in infection and trauma has not been delineated, treatment with human recombinant growth hormone (hrGH) has been shown to promote an anabolic response of body protein in various catabolic conditions including surgical trauma (17, $18)$ and sepsis $(19,20)$. In AIDS patients with extensive weight loss, treatment with 3-6 mg/d hrGH was associated with improved nitrogen retention over $7 \mathrm{~d}$ (21) and $12 \mathrm{wk}$ (22). Treatment with a lower dose of hrGH, however, $(0.68 \mathrm{mg} / \mathrm{d}) \mathrm{com}$ bined with $10 \mathrm{mg}$ IGF-I for 12 wk did not result in an improvement in total body protein mass in either control subjects or HIV+ individuals with at least $10 \%$ loss of body weight (23).

This study was undertaken to determine directly the anabolic response of muscle tissue to $\mathrm{hrGH}$ administration. It has previously been demonstrated that HIV+ individuals are fully able to respond to the anabolic stimulus provided by intravenous nutrition with an increase in protein synthesis and a decrease in protein degradation at the whole-body level (24). The response of the whole body, however, represents the sum of responses in individual tissues, and may mask a deficiency of response in muscle tissue, specifically. In this study, therefore, protein synthesis rates in vastus lateralis muscle were determined in control and HIV+ individuals before and two wk after treatment with hrGH.

\section{Methods}

Subjects. The study was approved by the Committee on Research Involving Human Subjects at Stony Brook. Both men and women were recruited: $26 \mathrm{HIV}+$ individuals and 9 healthy controls. Each HIV in-

1. Abbreviations used in this paper: 3-MH, 3-methyl histidine; CRC, Clinical Research Center; DEXA, duel-energy x-ray absorptiometry; hrGH, human recombinant growth hormone; LBM, lean body mass; REE, resting energy expenditure. 
dividual had documented evidence of HIV infection. Potential subjects were screened for metabolic abnormalities, including testosterone and thyroid levels, and excluded if values were outside the normal range. In addition, subjects with acute illness, active systemic opportunistic infection, diarrhea, malignancy, or recent surgery were excluded. Most, but not all subjects were taking antiretroviral therapy as well as a number of other medications including other antivirals, prophylactic antibiotics, antimycotics, and antimycobacterials, which were continued throughout the study period. Subjects on specific anabolic regimens (e.g., body-building, supplemental tube, or IV feeding) were also excluded.

HIV-infected patients are heterogeneous with respect to symptoms. In this study, HIV+ individuals were divided into three groups based on severity of disease. The group denoted HIV included individuals who were HIV + but asymptomatic; the group denoted AIDSno weight loss included individuals who had CD4+ counts $<200$, but without significant weight loss. Some of these individuals had previously been treated for characteristic opportunistic infections including cytomegalovirus (CMV) (1), pneumocystis carinii pneumonia (PCP) (1), esophageal candidiasis (1), and mycobacterium avium intracellulare (MAI) (1). The group denoted AIDS-weight loss included individuals with CD4+ counts $<200$, and weight loss $>10 \%$ of preillness body weight (mean weight loss, $19.2 \pm 2.2 \%$ [SEM]). Five of these patients had been weight-stable for 6 mo before study, and one patient had gradually lost weight at a rate of $<1 \mathrm{~kg}$ per mo for the preceding 3 mo. The patients in this group also had previously been treated for opportunistic infections including bacterial pneumonia (1), MAI (1), CMV (1), and PCP (1). The mean time of known HIV infection before the study date was similar for all three groups: $4.4 \pm 1 \mathrm{yr}$ for HIV, $4.7 \pm 0.6 \mathrm{yr}$ for AIDS, and $3.5 \pm 1 \mathrm{yr}$ for AIDS with weight loss.

Protocol. Before admission to the Clinical Research Center, (CRC) subjects consumed a meat-free diet for $3 \mathrm{~d}$ and collected urine for the last $24 \mathrm{~h}$ of that period. Arriving at $1700 \mathrm{~h}$, subjects were assessed clinically, including measurements of LBM by dual-energy x-ray absorptiometry (DEXA, model DPX; Lunar Radiation, Madison, WI), and muscle function. At $0600 \mathrm{~h}$ the next morning, measurements of resting energy expenditure were undertaken, followed by blood sampling for determination of IGF-I levels, TNF $\alpha$, and HIV load. Muscle protein synthesis was then measured by injection of $\mathrm{L}-\left[{ }^{2} \mathrm{H}_{5}\right]$ phenylalanine. After insertion of two IV cannulae into contralateral forearm veins, $45 \mathrm{mg} \mathrm{L}-\left[{ }^{2} \mathrm{H}_{5}\right.$, ring $]$ phenylalanine per $\mathrm{kg}$ body wt was injected over $10 \mathrm{~min}$. Labeled phenylalanine was given as a $2 \%$ solution in $0.45 \%$ saline with $10 \%$ L- $\left[{ }^{2} \mathrm{H}_{5}\right]$ phenylalanine (MassTrace, Woburn, MA) and unenriched phenylalanine (Ajinomoto, Raleigh, NC). Blood samples were taken at intervals over 90 min to determine plasma L- $\left[{ }^{2} \mathrm{H}_{5}\right]$ phenylalanine enrichment, and a percutaneous biopsy of vastus lateralis muscle was taken at $90 \mathrm{~min}$ and immediately frozen in liquid nitrogen (25).

All subjects were taught to administer $6 \mathrm{mg}$ hrGH (Serostim; generously provided by Serono Laboratories, Norwell, MA) as daily subcutaneous injections for $14 \mathrm{~d}$. In addition, subjects were provided with dietary advice, including sample menus, on how to achieve an energy intake equivalent to $1.5 \times$ basal energy expenditure (from HarrisBenedict predictive equations) with the goal of achieving $20 \%$ of energy from protein, $25 \%$ from fat, and $55 \%$ from carbohydrate with a protein intake of at least $1.5 \mathrm{~g}$ protein per $\mathrm{kg}$ of body wt (or ideal body wt if body wt was $<80 \%$ of ideal). During the 2 -wk hrGH treatment, subjects were monitored by telephone and returned to the CRC for biopsy wound assessment, blood glucose, and blood pressure monitoring. Immediately before the second admission, they also completed another $3 \mathrm{~d}$ with a meatless diet, and a 24-h urine collection on days $12-14$. The second admission to the CRC was also at $1700 \mathrm{~h}$ on the day before the study day, and the same protocol as described above was followed except that an additional muscle biopsy was taken before the injection of $\mathrm{L}-\left[{ }^{2} \mathrm{H}_{5}\right]$ phenylalanine for assessment of baseline labeling. The injection solution contained $20 \%$ enriched $\mathrm{L}-\left[{ }^{2} \mathrm{H}_{5}\right]$ phenylalanine.
Measurement of muscle function. A Cybex 6000 Isokinetic Dynamometer was used to measure peak muscle torque and work during reciprocal knee flexion and extension, and shoulder flexion and extension at 60 and 180 degrees per s. Testing was performed before and directly after the 2 -wk period of hrGH administration. For unilateral knee testing, the subject was stabilized and aligned appropriately, and permitted up to ten repetitions to familiarize themselves with the testing device. The testing protocol consisted of six repetitions at 60 degrees per s, followed by a 2-min rest, and then 15 repetitions at 180 degrees per $\mathrm{s}$ through an arc of motion from 10-100 degrees flexion. The subject was then stabilized and aligned properly for testing of shoulder flexion/extension in the supine position. The protocol was identical to the knee protocol, with the exception of only ten repetitions required at the fast (180 degrees per s) speed. Range of motion was limited from 10 degrees of extension to 100 degrees of flexion. Muscle function data compared among the groups was normalized for body wt and expressed as percent.

Resting energy expenditure. Respiratory gas analysis was performed on each subject between 0600 and $0700 \mathrm{~h}$ before measurement of muscle protein synthesis. All subjects had been fasted overnight, and were tested in a supine position in a quiet dark room. The patient's head was placed under a ventilated hood, and carbon dioxide and oxygen content of the expired air was determined every minute using a Deltatrac metabolic monitor (Sensor Medix, Yorba Linda, CA). Patients were monitored for 40-50 min, and steady-state results obtained during the final 10-min period were used for all subsequent calculations. Equipment was calibrated using known gas concentrations before studying each patient.

Protein synthesis. Measurement of muscle protein synthesis from the incorporation of a flooding amount of L- $\left[{ }^{2} \mathrm{H}_{5}\right]$ phenylalanine has been described in detail previously (25). Frozen samples of plasma and muscle tissue were analyzed as follows. Enrichment of plasma phenylalanine was determined after acid precipitation and cation-exchange chromatography by monitoring the ions at $\mathrm{m} / \mathrm{z} 336$ and 341 of the tertiary butyldimethylsilyl derivative. The enrichment of L- $\left[{ }^{2} \mathrm{H}_{5}\right]$ phenylalanine in muscle protein was determined after $0.2 \mathrm{~mol} /$ liter perchloric acid precipitation with extensive washing to remove free phenylalanine, hydrolysis with $6 \mathrm{M} \mathrm{HCl}$ at $110^{\circ} \mathrm{C}$ for $24 \mathrm{~h}$, enzymatic conversion to phenylethylamine (tyrosine decarboxylase; Sigma Chemical Co., St. Louis, MO), and solvent extraction. The ions at $m / z, 106$ and 109 of the $n$-heptafluorobutyryl derivative were monitored with a VG MD 800 quadrupole gas chromatography mass spectrometer (Fisons Instruments, Inc., Beverly, MA) in the splitless mode after electron ionization. With this instrument there is no need to adjust the measured enrichment for the size of the sample, as was necessary previously $(25,26)$. The rate or muscle protein synthesis, $\mathrm{k}_{\mathrm{s}}$ expressed as the $\%$ of the protein pool synthesized per $d$, was calculated from the formula:

$\mathrm{k}_{\mathrm{s}}=\mathrm{S}_{\mathrm{B}} \times 100 / \mathrm{A}$

where $S_{B}$ is the enrichment of phenylalanine in protein and $A$ is the area under the plasma enrichment vs. time curve.

Measurement of IGF-I. Concentration of IGF-I in serum was determined by radioimmunoassay after acid-ethanol extraction and cryoprecipitation to remove IGF-binding activity, as described previously (27). The IGF-I-specific antibody was supplied by the National Pituitary Program (28), and IGF-I standards were from Upstate Biotechnology Inc. (Lake Placid, NY).

Measurement of viral load. The viral load was measured in plasma from all HIV-infected patients by bDNA nucleic acid hybridization assay using the Quantiplex HIV-RNA assay (Chiron, Emeryville, CA). The lower limit of sensitivity of this assay is 10,000 equivalents $/ \mathrm{ml}$ of plasma. Samples were drawn immediately before the first dose of hrGH and after the last dose at week two. In brief, blood was anticoagulated with acid citrate dextrose, centrifuged, and the plasma clarified with a second centrifugation. Duplicate samples were frozen at $-70^{\circ} \mathrm{C}$ until analysis. Results were determined using 
the manufacturer's software. For statistical analysis, values below 10,000 were arbitrarily assigned a value of 10,000. Effect of hrGH treatment was assessed by ANOVA from the paired difference of the log transforms.

Measurement of $T N F \alpha$. Concentration of $\mathrm{TNF} \alpha$ in blood was measured immediately before administration of hrGH and at week 2 after the last dose of hrGH. TNF $\alpha$ levels were determined from duplicate samples of frozen sera using the Quantikine High Sensitivity ELISA kit (R\&D Systems, Minneapolis, MN).

Measurement of 3-methyl histidine and creatinine. 3-methyl histidine (3-MH) was determined by HPLC analysis on 24-h urine samples from subjects consuming a 3-d meat-free diet. In brief, urine samples were precipitated with perchloric acid and centrifuged to remove particulate material. Samples were then derivatized with fluorescamine, as previously described (29), before their injection. Urine samples were injected onto a Waters Novapak C18 column, and fluorescence was detected with a fluorometric detector (ABI Analytical, Ramsey, NJ) using an excitation wavelength of $375 \mathrm{~nm}$ and a longpass filter $>418 \mathrm{~nm}$. The isocratic mobile phase consisted of $1 \mathrm{M}$ phosphate buffer ( $\mathrm{pH}$ 6.5) and acetonitrile and water, 1:5:14; the flow rate was $1.0 \mathrm{ml} / \mathrm{min}$. Urinary $3-\mathrm{MH}$ was calculated based on an external 3-MH standard (Sigma Chemical Co.). Urinary creatinine concentration was determined using a standard colorimetric method (Sigma Chemical Co.).

Statistical analysis. The data are expressed as means and standard errors of the mean. Statistical evaluation of the means was by analysis of variance followed by the Student-Newman-Keuls test for multiple testing between individual groups, unless noted differently. Changes in values between the pre- and post hrGH measurements were made by the paired $t$ test.

\section{Results}

The patient characteristics including anthropometry, CD4+ counts, viral load, and TNF $\alpha$ levels of all subjects at the time of recruitment are shown in Table I. Those individuals with the most severe illness were on average slightly older than the control group ( $42 \pm 1.5$, range $35-45$ vs. $34 \pm 2.5$, range $28-46$ ). The HIV and AIDS with weight-loss groups had the smallest body mass indices (BMI, wt $/ \mathrm{h}^{2}$ ); but in the HIV group this was the result of the higher proportion of females in this group rather than the wasting seen in the AIDS with weight loss group. LBM determined by DEXA, however, was not significantly different among the groups. The \% body fat was lower in the AIDS with weight loss group $(15.4 \pm 3.0 \%)$ than in control
$(22.7 \pm 3.0 \%)$, HIV $(20.2 \pm 1.8 \%)$, and the AIDS without weight loss group $(21.4 \pm 1.8 \%)$ although the differences among the groups were not statistically significant. CD4+ levels were lower in both the AIDS and AIDS with weight loss groups than in the HIV group, and TNF $\alpha$ levels were significantly higher in the AIDS with weight loss group than in any of the other groups.

At screening, individuals who were hypogonadal were excluded so testosterone levels were normal in all four groups of subjects (in $\mu \mathrm{g} / \mathrm{dl}$; normal range 280-1080): control, 504 \pm 52 ; $\mathrm{HIV}+, 512 \pm 29$; AIDS without weight loss, 668 \pm 70 ; and AIDS with $>10 \%$ weight loss, $680 \pm 72$. Thyroid function assessed from TSH levels $(1.65 \pm 0.28,1.63 \pm 0.31,1.43 \pm 0.19$, and $2.37 \pm 0.85$ $\mathrm{UIU} / \mathrm{ml}$; normal range $0.4-5$ in control, HIV, AIDS, and AIDS weight loss, respectively) and free thyroxine index $(6.79 \pm 0.32$, $7.01 \pm 0.18,6.33 \pm 0.27$, and $7.15 \pm 0.22)$, were also in the normal range $(5-11)$.

Treatment with hrGH (6 mg/day) for 2 wk produced a statistically significant increase in body weight in all groups $(P<$ 0.001 , Table II). Although there were individual differences in the amount of weight gained, there was no obvious difference among the groups. There was a dramatic fourfold increase in IGF-I in all the subjects studied in response to $\mathrm{hrGH}(P<$ 0.001 ) with no discernibly different level of stimulation among the groups. Resting energy expenditure, expressed per $\mathrm{kg}$ of lean body mass derived from the DEXA measurement, was also increased by hrGH treatment $(P<0.001$, paired $t)$, with similar increases observed among the groups. Viral load was not significantly affected by treatment with this dose of hrGH.

Muscle protein synthesis in the basal pre-hrGH state was not different between the control subjects and all the HIV+ individuals (Table III). Moreover, even after progression to AIDS with weight loss, there was no observable depression of the basal rate of muscle protein synthesis. In the 35 individuals studied, there was also no correlation of the initial rate of muscle synthesis with either age or gender.

Treatment with hrGH produced a large (27\%) stimulation in protein synthesis in the control subjects (Table III). Unlike the responses of IGF-I and REE, however, the response to hrGH was not similar across all the groups. There were progressively smaller increases in groups with increasing severity of disease, so that in the AIDS plus weight loss group, protein synthesis actually fell significantly after hrGH (paired $t, P<$

Table I. Characteristics of Subjects

\begin{tabular}{|c|c|c|c|c|}
\hline & Control & HIV & AIDS, no wt loss & AIDS, wt loss \\
\hline & $n=9$ & $n=9$ & $n=11$ & $n=6$ \\
\hline $\mathrm{m} / \mathrm{f}$ & $7 \mathrm{~m}, 2 \mathrm{f}$ & $5 \mathrm{~m}, 4 \mathrm{f}$ & $10 \mathrm{~m}, 1 \mathrm{f}$ & $6 \mathrm{~m}$ \\
\hline age (yr) & $34 \pm 2.5^{\mathrm{a}}$ & $35 \pm 3$ & $39 \pm 1$ & $42 \pm 1.5^{\mathrm{a}}$ \\
\hline ht (m) & $1.69 \pm 0.02$ & $1.68 \pm 0.02$ & $1.76 \pm 0.03$ & $1.76 \pm 0.03$ \\
\hline wt (kg) & $72 \pm 3$ & $62 \pm 2$ & $73 \pm 3.5$ & $62 \pm 3$ \\
\hline BMI $\left(\mathrm{kg} / \mathrm{m}^{2}\right)$ & $25 \pm 1^{\mathrm{b}, \mathrm{c}}$ & $22 \pm 1^{\mathrm{b}}$ & $23 \pm 0.5$ & $20 \pm 1^{\mathrm{c}}$ \\
\hline $\operatorname{LBM}(\mathrm{kg})$ & $55.07 \pm 3.15$ & $47.14 \pm 1.96$ & $55.03 \pm 2.74$ & $50.61 \pm 2.32$ \\
\hline $\mathrm{CD} 4+\left(\right.$ cells $\left./ \mathrm{mm}^{3}\right)$ & ND & $576 \pm 94^{\mathrm{d}, \mathrm{e}}$ & $123 \pm 26^{\mathrm{d}}$ & $93 \pm 56^{\mathrm{e}}$ \\
\hline $\mathrm{TNF} \alpha$ (ng/liter) & $2.64 \pm 0.34^{\mathrm{f}}$ & $6.01 \pm 1.54^{\mathrm{g}}$ & $6.15 \pm 0.45^{\mathrm{h}}$ & $13.33 \pm 4.07^{\mathrm{f}, \mathrm{g}, \mathrm{h}}$ \\
\hline
\end{tabular}

The data are all expressed as means \pm SEM. Subjects were recruited into the study and assigned to a group based on severity of disease. The group HIV (group 1) were HIV+ but asymptomatic. AIDS, no weight loss individuals were those individuals who had an AIDS-defining illness, but without weight loss (group 2), and AIDS, weight loss were individuals with AIDS and weight loss $>10 \%$ (group 3). Body mass index (BMI) is weight/height ${ }^{2}$. Lean body mass was determined by DEXA. Groups with the same superscripts are significantly different, $P<0.05$. ND, not determined. 


\begin{tabular}{|c|c|c|c|c|}
\hline & Control & $\mathrm{HIV}+$ & AIDS & AIDS, wt loss \\
\hline & $n=9$ & $n=9$ & $n=11$ & $n=6$ \\
\hline Weight gain $(\mathrm{kg})$ & $2.79 \pm 0.53^{\mathrm{a}}$ & $1.98 \pm 0.47^{\mathrm{a}}$ & $2.61 \pm 0.3^{\mathrm{a}}$ & $1.97 \pm 0.46^{\mathrm{a}}$ \\
\hline IGF-I, basal (ng/ml) & $138 \pm 17.7$ & $141 \pm 18.4$ & $119 \pm 17$ & $154 \pm 28.9$ \\
\hline IGF-I, post GH (ng/ml) & $537 \pm 57^{\mathrm{b}}$ & $488 \pm 61^{\mathrm{b}}$ & $584 \pm 75^{\mathrm{b}}$ & $630 \pm 204^{\mathrm{b}}$ \\
\hline REE, basal(kcal/kgLBM/d) & $30.84 \pm 0.93$ & $33.16 \pm 0.85$ & $32.64 \pm 0.91$ & $29.72 \pm 2.14$ \\
\hline REE, post GH (kcal/kgLBM/d) & $37.39 \pm 2.02$ & $38.49 \pm 0.87$ & $39.2 \pm 1.4$ & $36.08 \pm 2.45$ \\
\hline Viral load, basal (equiv/ml) & ND & $19400 \pm 7440$ & $54600 \pm 30000$ & $39500 \pm 13200$ \\
\hline Viral load, post GH (equiv/ml) & ND & $20400 \pm 7830$ & $44160 \pm 16500$ & $33500 \pm 12300$ \\
\hline
\end{tabular}

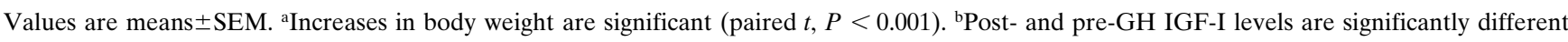
(paired $t, P<0.001$ ). REE is expressed per kg LBM from DEXA measurement. For all groups combined, basal vs. post GH, $P<0.001$, paired $t$. The paired difference in viral load (after log transformation) between the post $\mathrm{GH}$ and basal values was not significantly different in any of the groups. $\mathrm{ND}$, not determined.

0.03). These responses to hrGH were significantly different among the groups when analyzed as paired differences (Table III). A similar statistical analysis is obtained from an evaluation of the proportional increases in protein synthesis.

Fig. 1 illustrates the correlation of the change in muscle protein synthesis during the $2 \mathrm{wk}$ of hrGH treatment vs. progression of the disease. Because the assignment of individuals to particular groups was discrete rather than continuous, statistical evaluation of the correlation in Fig. 1 was done with the nonparametric, Spearman rank correlation, which showed a highly significant relationship $(P=0.002)$.

Because of the disparity in mean age between the control and AIDS with weight loss groups, the effect of age on stimulation of muscle protein synthesis by hrGH was also examined. Fig. 2 demonstrates that the stimulation in muscle protein synthesis in response to hrGH was not influenced by the age of the subject. The effect of gender on the responsiveness of muscle protein synthesis is difficult to assess with the small numbers of HIV+ females in the study. In general, however, the responsiveness of female subjects was similar to male subjects within the groups. Thus, the unequal gender distribution in the groups is unlikely to have influenced the overall result. Removing females from the correlation of response with disease severity (Fig. 1) does not lose the significance, although it increases the $P$ value to 0.006 .

Table III. Changes in Muscle Protein Synthesis in Response to Growth Hormone Treatment

\begin{tabular}{lccc}
\hline & $\mathrm{k}_{\mathrm{s}}$, initial & $\mathrm{k}_{\mathrm{s}}$, post GH & Paired difference* \\
\hline Control $(n=9)$ & $1.717(0.061)$ & $2.147(0.151)$ & $0.430(0.190)^{\mathrm{a}}$ \\
HIV+ $(n=9)$ & $1.602(0.134)$ & $1.936(0.348)$ & $0.334(0.243)^{\mathrm{b}}$ \\
AIDS $(n=11)$ & $1.860(0.141)$ & $1.545(0.170)$ & $-0.314(0.240)$ \\
AIDS, wt loss $(n=6)$ & $2.081(0.306)$ & $1.229(0.286)$ & $-0.853(0.280)^{\mathrm{a}, \mathrm{b}}$
\end{tabular}

Muscle protein synthesis is expressed as a fractional rate, $\mathrm{k}_{\mathrm{s}}$, in \% per day (SEM). The initial measurement was made before growth hormone treatment. Post GH measurements were made after $14 \mathrm{~d}$ of GH $(6 \mathrm{mg} / \mathrm{d})$. The difference between the first and second measurements is expressed as the paired difference. Groups indicate increasing severity of disease (see description in the legend to Table I). Groups with the same superscripts are significantly different, $P<0.05$ (Student-Newman-Keuls).
The two groups, AIDS-no weight loss and AIDS-weight loss, included individuals who had been previously treated for opportunistic infections and those who had not. There was, however, no difference in the response of muscle protein synthesis to hrGH between those who had previous infections and those who had not. Within the HIV+ groups there was also heterogeneity with respect to antiretroviral treatment, but in none of the groups was there a difference in response between individuals taking these drugs vs. those who were not. Three individuals were taking protease inhibitors at the time of the study. The response of muscle protein synthesis to hrGH in these individuals was comparable to the others of their respective groups; that is, none of these individuals responded like the control subjects with increased muscle protein synthesis in response to hrGH. Although there were higher levels of TNF $\alpha$ in the AIDS with weight loss group (Table I), there was no statistical correlation between TNF $\alpha$ levels and the magnitude of the response of muscle protein synthesis to hrGH treatment.

Myofibrillar protein degradation was assessed from urinary

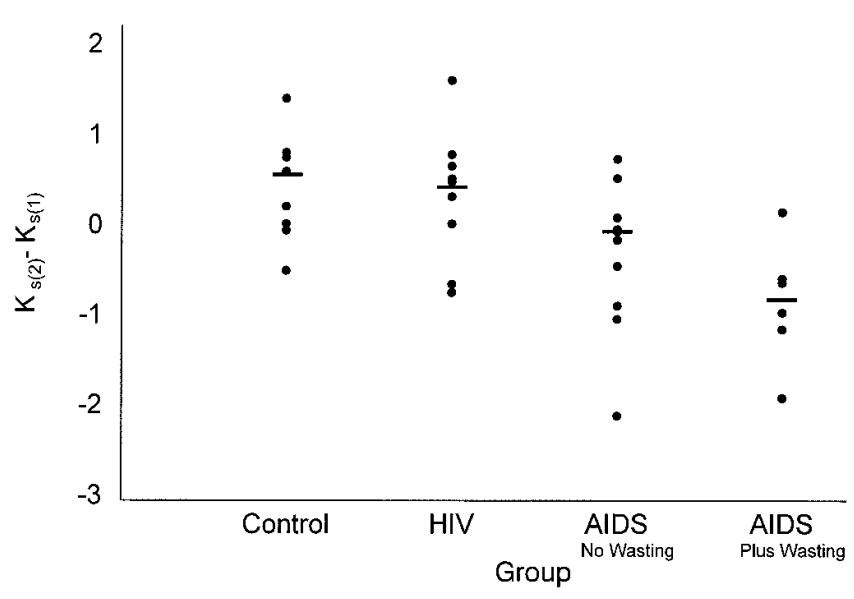

Figure 1. Correlation of the response of muscle protein synthesis to hrGH in HIV + individuals by severity of disease. Muscle protein synthesis is expressed as the difference in fractional synthesis rate (\% per day) before $\left(\mathrm{k}_{\mathrm{s}(1)}\right)$ and after $\left(\mathrm{k}_{\mathrm{s}(2)}\right)$ treatment with $6 \mathrm{mg} / \mathrm{d} \mathrm{hrGH}$. The groups are explained in the legend to Table I. The correlation is significant, $P=0.002$ (Spearman rank correlation). 


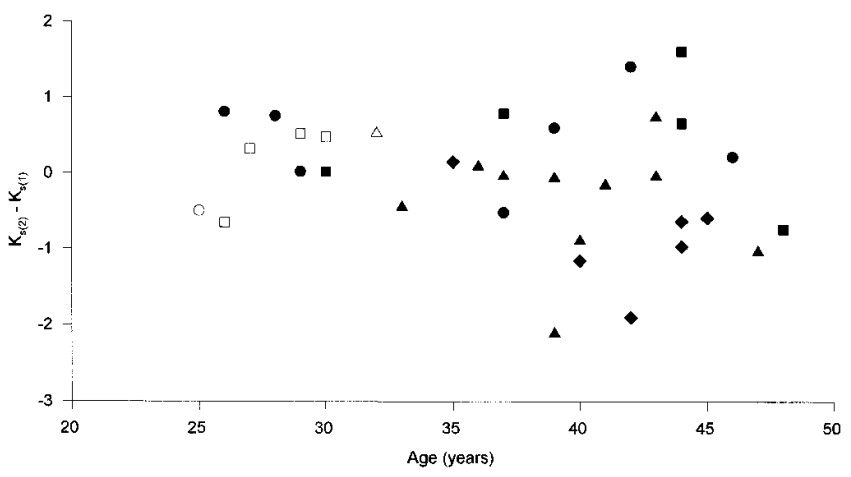

Figure 2. Correlation of the response of muscle protein synthesis to $\mathrm{hrGH}$ in HIV+ individuals with age. Muscle protein synthesis is expressed as the difference in fractional synthesis rate (\% per day) before $\left(\mathrm{k}_{\mathrm{s}(1)}\right)$ and after $\left(\mathrm{k}_{\mathrm{s}(2)}\right)$ treatment with $6 \mathrm{mg} / \mathrm{d} \mathrm{hrGH}$ in control $(\bullet)$, HIV $+(\boldsymbol{\square})$, AIDS, no wt loss $(\bullet)$, and AIDS, wt loss $(\bullet)$ subjects. Female subjects are shown as open symbols. The correlation with age is not significant.

3-MH excretion with the subjects consuming a meat-free diet. Excretion of 3-MH shown in Table IV is expressed as a ratio to urinary creatinine to correct for possible incomplete recovery of urine, and for disparity in muscle mass between individuals. Basal excretion of 3-MH was higher in each of the two groups of AIDS individuals than in either the controls or HIV+ individuals (Table IV). Although there was an increase in 3-MH excretion overall after hrGH treatment of $16 \pm 0.06 \%(P=$ 0.035 by paired $t$ ), the increase in $3-\mathrm{MH}$ was greatest in the healthiest individuals (controls and HIV+) with smaller increases in the AIDS individuals with and without weight loss. This trend, however, was not statistically significant.

Compared to control subjects, the basal level of muscle function normalized for body weight was lower in all infected individuals ( $\mathrm{HIV}+$, AIDS no wt loss, and AIDS wt loss). A significant depression was found in peak torque and work for both knee extension and shoulder flexion measured at two speeds when compared with controls $(P<0.05)$. The data for knee extension are shown in Fig. 3. Similar patterns of reduced function were also observed with knee flexion and shoulder extension, although the data did not reach statistical significance.

Table IV. Changes in 3-Methyl Histidine Excretion (Expressed as 3-MH/Creatinine [Cr] Excretion $\times 1000)$ in Response to Growth Hormone Treatment

\begin{tabular}{lccr}
\hline & Basal 3-MH/Cr & Post GH 3-MH/Cr & Paired difference \\
\hline Control $(n=11)$ & $14.5 \pm 0.8^{\mathrm{a}, \mathrm{b}}$ & $17.3 \pm 1.2$ & $2.77 \pm 1.32$ \\
HIV+ $(n=9)$ & $14.9 \pm 2.0^{\mathrm{c}, \mathrm{d}}$ & $19.2 \pm 1.7$ & $4.29 \pm 1.64$ \\
AIDS $(n=12)$ & $19.9 \pm 0.8^{\mathrm{a}, \mathrm{c}}$ & $20.8 \pm 1.3$ & $0.96 \pm 1.76$ \\
AIDS, wt loss $(n=7)$ & $20.2 \pm 1.2^{\mathrm{b}, \mathrm{d}}$ & $19.9 \pm 1.4$ & $-0.34 \pm 1.60$
\end{tabular}

Values are means \pm SEM based on 24-h urine collections on the last of $3 \mathrm{~d}$ on a meat-free diet. Data was collected before and after $2 \mathrm{wk}$ of daily injections of $6 \mathrm{mg}$ of hrGH. The groups are explained in the legend to Table I. Groups with the same superscripts are statistically significantly different $(P<0.05$, Student-Newman-Keuls $)$.
After hrGH treatment, 8 of the 16 measured parameters of muscle function were significantly improved in control subjects. These included knee extension at $180^{\circ} / \mathrm{s}$ for torque and work $(P<0.05)$, knee flexion at $60^{\circ}$ and $180^{\circ}$ s for torque $(P<$ $0.01)$ and work $(P<0.03)$, and shoulder extension at $180^{\circ}$ s for torque and work $(P<0.01)$. In the HIV + group, torque for knee extension at $180^{\circ} / \mathrm{s}$ was improved $(P<0.02)$ as was work for knee extension at $60^{\circ} / \mathrm{s}$. Improvement in the AIDS group was noted for knee flexion at $60^{\circ} / \mathrm{s}$ for work $(P<0.01)$, and for knee flexion at $180^{\circ} / \mathrm{s}$ for torque and work $(P<0.01)$, whereas in the AIDS weight loss individuals, improvement with hrGH was only observed in knee extension at $60^{\circ} / \mathrm{s}(P<0.01)$.

\section{Discussion}

This study demonstrates a defect in the response of muscle protein synthesis to hrGH in subjects with AIDS wasting which is not observed in healthy individuals or in HIV+ individuals without AIDS (Fig. 1). Although the rate of muscle protein synthesis increased by $27 \%$ in control subjects and by $11 \%$ in HIV + , asymptomatic individuals, this effect was progressively diminished with the increasing severity of the disease (Table III and Fig. 1). This progressive decline in the stimulation of protein synthesis with increased severity of disease may explain the clinical finding that individuals with AIDS wasting are unresponsive to hrGH (23) at levels that are used for hrGH replacement in hrGH-deficient adults $(0.006$ $0.0125 \mathrm{mg} / \mathrm{kg} / \mathrm{d})$, but show improved nitrogen balance with much higher levels $(3-6 \mathrm{mg} / \mathrm{d} ; 21,22)$. These data also show that AIDS wasting is clearly different from other catabolic states such as hypocaloric feeding (30-32), surgery (33), cancer cachexia (34), glucocorticoid treatment $(35,36)$, and burns $(37)$, where hrGH has proven effective in counteracting the catabolic effects on muscle metabolism or the loss of body protein.

This decline in the anabolic response to hrGH in muscle tissue does not arise from a generalized resistance to the effect of hrGH, as there are demonstrable whole-body responses to hrGH in HIV+ individuals such as elevated resting energy expenditure (Table II). Moreover, the ability of the liver to produce IGF-I in response to elevated levels of hrGH was compa-
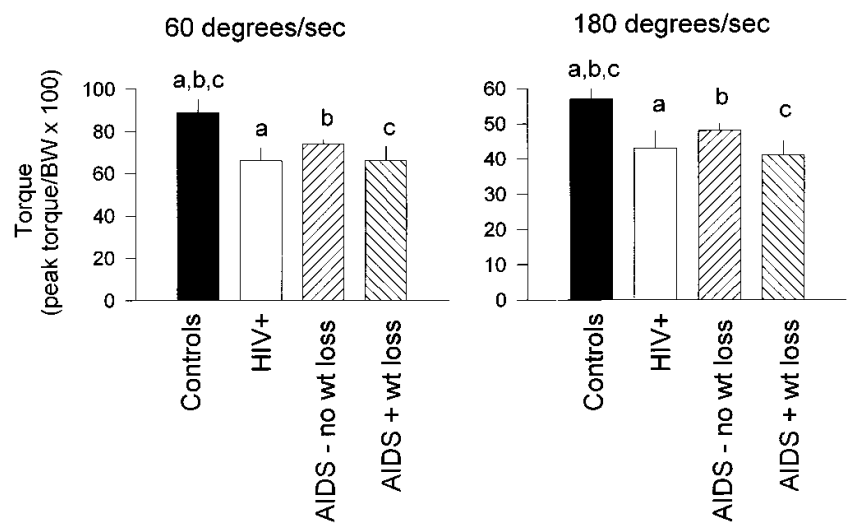

Figure 3. Peak torque of knee extension at 60 and 180 degrees/s expressed as torque/body wt $\times 100$ in control and HIV + individuals. The subject groups are explained in the legend to Table I. Groups marked with the same letter are significantly different $(P<0.05$, Student-Newman-Keuls). 
rable at all stages of disease (Table II). The inability of the muscle to respond to the anabolic stimulus of hrGH, therefore, seems to be specific to this tissue. Blunting of this, and possibly other anabolic stimuli, on muscle during AIDS wasting might therefore explain the selective loss of lean tissue observed in these individuals $(1,14,15)$.

There was not, however, a generalized failure of muscle to synthesize protein in individuals with AIDS plus weight loss. The basal rates of protein synthesis were similar in control subjects, in individuals with HIV infection, and even with progression to AIDS wasting (Table III). This ability to maintain protein synthesis rates at normal levels contrasts with other catabolic states, such as the trauma imposed by surgery, where rates of muscle protein synthesis were depressed by $30-50 \%$ (16). Therefore, alteration in muscle protein metabolism in AIDS involves a defect in response to an anabolic stimulus, rather than a more generalized failure to synthesize protein.

It is tempting to conclude that increased levels of TNF $\alpha$ in the weight loss group contributed to the failure of hrGH to promote an anabolic response in muscle. Elevated levels of $\mathrm{TNF} \alpha$ and soluble $\mathrm{TNF} \alpha$ receptors that correlated with the stage of disease have been observed in AIDS patients (38), and this cytokine has been suggested as a potential mediator in AIDS wasting (for review see references 39 and 40). In cultured human myoblasts, TNF $\alpha$ prevented stimulation of protein synthesis by IGF-I (41). Moreover, TNF $\alpha$ injections into animals have shown both depressed muscle protein synthesis (42) and enhanced muscle protein degradation (43). The depression in protein synthesis in response to $\mathrm{hrGH}$ in this study, however, did not correlate with the measured circulating TNF $\alpha$ levels in individual subjects. Suppression of muscle protein synthesis was observed in individuals with $\mathrm{TNF} \alpha$ levels that were comparable to those in other individuals displaying significant stimulation in muscle protein synthesis. Given the complexity of the immune system to produce proinflammatory cytokines including interleukins- 1 and -6 and interferon $\gamma$, it is probably too simplistic to view inhibition of muscle protein synthesis by hrGH as arising solely from increased circulating levels of TNF $\alpha$ (for review see reference 44).

In this study it is not possible to differentiate between an inability of patients with AIDS wasting to respond to the anabolic effects of hrGH-induced IGF-I or a failure to respond to more direct effects of hrGH independent of the elevated IGF-I levels. Studies in healthy individuals designed to assess the immediate effects (within $3 \mathrm{~h}$ ) of IGF-I on muscle protein metabolism have suggested that the ability of hrGH to stimulate muscle protein synthesis is not entirely mediated through increased circulating levels of IGF-I, since local (brachial arterial) infusion of hrGH increased muscle protein synthesis without elevating systemic levels of IGF-I (45). Moreover, although high levels of IGF-I from local infusion of IGF-I increased muscle protein synthesis in the infused arm, the more moderate levels in the systemic circulation (more comparable to those with systemic GH infusion; 46) had no effect in the control $\operatorname{arm}(47)$.

Net accumulation or loss of protein from a tissue is determined by the balance between the rates of protein synthesis and rates of protein degradation. In this study, 3-MH excretion (a measure of muscle protein degradation in the whole body) before hrGH was higher in both groups of AIDS individuals, including those with and without weight loss, than in control subjects. Although protein synthesis rates were normal, the en- hanced rates of myofibrillar protein degradation would result in persistent loss of muscle mass from these individuals. Although it has been suggested that after major surgery not all 3-MH production arises from the degradation of skeletal myofibrillar protein (48), more recent studies comparing the output of 3-MH from the leg and gut with urinary 3-MH excretion in patients with various infections have demonstrated the usefulness of urinary 3-MH excretion as a marker of myofibrillar protein catabolism (49).

In this study, 2 wk of hrGH treatment increased the rate of muscle protein degradation, assessed from 3-MH excretion, by an average of $16 \%$ across all the groups, with the largest stimulation, $28 \pm 8 \%$, in the control and HIV+ groups, and much smaller, statistically nonsignificant changes in the AIDS groups. The increase in protein degradation in the control and HIV+ groups would tend to offset the stimulation in protein synthesis observed in these individuals (Table III), so that the accumulation of muscle protein would be less than that suggested by the enhancement of synthesis alone. Correspondingly, the catabolic effect on muscle protein synthesis in the AIDS groups (Table III) would also tend to be moderated by the fact that protein degradation was not enhanced by hrGH in these individuals. Concurrent changes in protein synthesis and degradation have been observed in other anabolic conditions such as those that accompany normal growth (50) or increased muscle mass brought about by resistance training (51) when both synthesis and degradation of muscle are stimulated, with the increase in protein synthesis exceeding the increase in degradation. Although a direct effect of hrGH on muscle protein degradation has not been reported, Fryburg et al. (52) have demonstrated an enhancement in muscle protein degradation by hrGH through an inhibition of insulin's suppressive effect on muscle proteolysis.

In all three groups of infected individuals, muscle function was reduced when compared with controls before hrGH treatment (Fig. 3). The differences in the basal muscle function were most apparent for knee extension and shoulder flexion, which may suggest a deficit specifically in muscles that mainly function against gravity. With 2 wk of hrGH treatment, muscle function was demonstrably improved in control subjects in 8 of 16 parameters measured. Although muscle function in control subjects improved with the 2-wk treatment regimen, this period was not long enough to demonstrate the same degree of improvement in HIV+ and AIDS patients. It is likely, however, that with a longer period of treatment these patients would also show an improvement in muscle function, as has been previously demonstrated $(22,53)$.

The lack of an anabolic response in muscle protein synthesis to hrGH treatment in AIDS individuals with weight loss appears to contrast with other studies demonstrating improved nitrogen balance with hrGH treatment for $7 \mathrm{~d}$ (21) and increased LBM and improved muscle function after 12 wk of treatment $(22,53)$. Improved muscle function and increased LBM with 12 wk of hrGH (53), however, are not necessarily inconsistent with the measurements of depressed muscle protein synthesis. It may be that hrGH regulation of muscle protein occurs primarily through effects on protein degradation rather than protein synthesis. Moreover, it is also possible that longer treatment regimens, such as $12 \mathrm{wk}$, would impact positively on muscle protein synthesis. These data should not be interpreted to mean that anabolic agents such as hrGH are not useful in patients with AIDS wasting. They do, however, sug- 
gest that a greater anabolic response might be observed earlier in the course of the disease.

The resting energy expenditure (REE) measured before $\mathrm{hrGH}$ treatment, expressed per $\mathrm{kg}$ lean body mass derived from the DEXA measurement, showed no correlation with age or severity of disease. The lack of an age effect may well be due to the fact that age-related changes in body composition are removed from the analysis by expressing the data per $\mathrm{kg}$ lean body mass as determined by DEXA. The lack of a demonstrable increase in REE with HIV+ infection is not consistent with a study of Macallan et al. (54), who reported an increase of $14 \%$ in REE, expressed per kg lean body mass determined by anthropometry. The difference between these two studies, however, may arise from the inherent heterogeneity of $\mathrm{HIV}+$ populations. Rather than studying patients at a time when they were weight-stable and free of active opportunistic infections as was done in this study, Macallan et al. (54) included individuals who were actively losing weight with cancer, secondary infections, febrile illness, and diarrhea. These patients were more ill than the ones in this study, which probably accounts for the different observations of REE.

In response to $2 \mathrm{wk}$ of hrGH treatment, all subjects showed an increase in REE $(21 \pm 2 \%)$, and this increase in REE was not correlated with either the age of the subjects or the severity of disease. This increase in REE is consistent with previous reports of responses to hrGH $(21,55,56)$ or IGF-I treatment (57), and may be due in part to increased energy expenditure associated with increased anabolic processes such as protein turnover. It is clear that all subjects, including those with the most advanced disease, were responsive to the effects of hrGH on energy metabolism as well as liver production of IGF-I, which increased fourfold in response to hormone treatment.

In conclusion, this study demonstrates two aspects of muscle metabolism that contribute to the loss of muscle protein in AIDS wasting. In AIDS patients there was increased degradation of myofibrillar protein, as evidenced by higher excretion of 3-MH, under basal conditions. With normal rates of protein synthesis in these individuals, the increased rates of protein degradation would lead to continued loss of muscle protein. In addition to the higher rates of muscle protein degradation in the basal state, individuals with AIDS and weight loss were also insensitive to the anabolic effects of short-term hrGH treatment over a 2-wk period observed both in healthy subjects and in HIV + individuals before weight loss. This second observation has important clinical implications for the use of hrGH to restore body protein mass in wasted individuals with HIV infection. To be most efficacious, the results suggest that hrGH administration might need to precede the onset of weight loss.

\section{Acknowledgments}

We would like to thank Dr. Monica Scantlebury and the nursing staff of the CRC for their assistance in carrying out these studies. The willingness of our surgical colleagues, Drs. Peter Bongiovanni, Evan Geller, Mark Gestring, and Acram Talhouk, to donate so many of their early morning hours is also most appreciated. Skillful assistance was provided by Barbara Craddock, George Casella, and Yuqun Hong. Serono Laboratories generously provided both the Serostim for the study and a small travel grant.

This work was supported by National Institutes of Health grant DK 49316-01 (M.C. Gelato) and a National Institutes of Healthsponsored Institutional Research Service Award T32DK07521 to the
Diabetes and Metabolic Diseases Research Program, Stony Brook (R.A. Frost).

\section{References}

1. Kotler, D.P., J. Wang, and R. Pierson. 1985. Studies of body composition in patients with the acquired immunodeficiency syndrome. Am. J. Clin. Nutr. 42:1255-1265.

2. Serwadda, D., N.K. Sewankambo, J.W. Carswell, A.C. Bayley, R.S. Tedder, R.A. Weiss, A. Lwegaba, G.B. Kirya, R.G. Downing, S.A. Clayden, and A.G. Dalgleish. 1985. Slim disease: a new disease in Uganda and its association with HTLV-III infection. Lancet. ii:850-852.

3. Chlebowski, R.T., M.B. Grosvenor, N.H. Berhard, L.S. Morales, and L.M. Bulcavage. 1989. Nutritional status, gastrointestinal dysfunction, and survival in patients with AIDS. Am. J. Gastroenterol. 84:1288-1293.

4. Guenter, P., N. Muurahainen, G. Simons, A. Kosok, G.R. Cohan, R. Rudenstein, and J.L. Turner. 1993. Relationships among nutritional status, disease progression and survival in HIV infection. J. Acquired Immune Defic. Syndr. 6:1130-1138.

5. Anonymous. 1987. Revision of the CDC surveillance case definition for acquired immunodeficiency syndrome. Morbid. Mortal. Wkly Rep. 36:3-15.

6. Cutler, D.P., A.R. Tierney, A. Francisco, J. Wang, and R.N. Pierson, Jr. 1989. The magnitude of body cell mass depletion determines the timing of death from wasting in AIDS. Am. J. Clin. Nutr. 50:444-447.

7. Palanicek, J.P., N.M.H. Graham, Y.D. He, D.A. Hoover, J.S. Oishi, L. Kingsley, and A.J. Saah. 1995. Weight loss prior to clinical AIDS as a predictor of survival. J. Acquired Immune Defic. Syndr. 10:366-373.

8. Turner, J., N. Muurahainen, C. Terrell, C. Graeber, and C. Kotler. 1994 Nutritional status and quality of life. Int. Conf. AIDS. 2:35 (Abstr.).

9. Cohan, G.R., N. Muurahainen, P. Guenter, A. Kosok, and J.L. Turner. 1992. HIV-related hospitalizations, CD4 percent and nutritional markers. Int. Conf. Acquired Immune Defic. Syndr. 1:67 (Abstr.).

10. Süttman, U., J. Ockenga, O. Selberg, L. Hoogestraat, H. Deicher, and M.J. Müller. 1995. Incidence and prognostic value of malnutrition and wasting in HIV-infected outpatients. J. Acquired Immune Defic. Syndr. 8:239-246.

11. Ott, M., H. Fischer, H. Polat, E.B. Helm, M. Frenz, W.F. Caspary, and B. Lembcke. 1995. Bioelectrical impedance analysis as a predictor of survival in patients with human immunodeficiency virus infection. J. Acquired Immune Defic. Syndr. 9:20-25.

12. Pisters, P.W., and D.B. Pearlstone. Protein and amino acid metabolism in cancer cachexia: investigative techniques and therapeutic interventions. 1993. Crit. Rev. Clin. Lab. Sci. 30:223-272.

13. Garlick, P.J., and J. Wernerman. 1997. Protein metabolism in injury. In Scientific Foundations of Trauma. G. Cooper, H. Dudley, R. Little, and R. Maynard, editors. Butterworth/Heineman, Oxford.

14. Ott, M., B. Lembck, H. Fischer, R. Jager, H. Polat, H. Geier, M. Rech, S. Staszeswki, E.B. Helm, and W.F. Caspary. 1993. Early changes of body composition in human immunodeficiency virus-infected patients; tetrapolar body impedance analysis indicates significant malnutrition. Am. J. Clin. Nutr. 57:15-19.

15. Grunfeld, C., and K.R. Feingold. 1992. Seminars in medicine of the Beth Israel Hospital, Boston. Metabolic disturbances and wasting in the acquired immunodeficiency syndrome. N. Engl. J. Med. 327:329-337.

16. Essen, P., M.A. McNurlan, T. Sonnenfeld, E. Milne, E. Vinnars, J. Wernerman, and P.J. Garlick. 1993. Muscle protein synthesis after operation: the effects of intravenous nutrition. Eur. J. Surg. 159:195-200.

17. Ward, H.C., D. Halliday, and A.J.W. Sim. 1987. Protein and energy metabolism with biosynthetic human growth hormone after gastrointestinal surgery. Ann. Surg. 206:56-61.

18. Mjaaland, M., K. Unneberg, R. Hotvedt, and A. Revhaug. 1991. Nitrogen retention caused by growth hormone in patients undergoing gastrointestinal surgery with epidural analgesia and parenteral nutrition. Eur. J. Surg. 157: 21-27.

19. Douglas, R.G., D.A. Humberstone, A. Haystead, and J.H.F. Shar. 1990. Metabolic effects of recombinant human growth hormone: isotopic studies on the postabsorptive state and during total parenteral nutrition. Br. J. Surg. 77: $785-790$.

20. Voerman, H.J., R.J. Strack van Schijndel, A.B. Johan Groeneveld, H. de Boer, J.P. Nauta, and L.G. Thijs. 1995. Effects of human growth hormone in critically ill nonseptic patients: Results from a prospective, randomized, placebo-controlled trial. Crit. Care Med. 23:665-673.

21. Mulligan, K., C. Grunfeld, M.K. Hellerstein, R.A. Neese, and M. Schambelan. 1993. Anabolic effects of recombinant human growth hormone in patients with wasting associated with human immunodeficiency virus infection. J. Clin. Endocrinol. Metab. 77:956-962.

22. Krentz, A.J., F.T. Koster, D.M. Crist, K. Finn, L.Z. Johnson, P.J. Boyle, and D.S. Schade. 1993. Anthropometric, metabolic, and immunological effects of recombinant human growth hormone in AIDS and AIDS-related complex. $J$. Acquired Immune Defic. Syndr. 6:245-251.

23. Ellis, K.J., P.D.K. Lee, J.M. Pivarnik, J.G. Bukar, and N. Gesundheit 1996. Changes in body composition of human immunodeficiency virus-infected males receiving insulin-like growth factor I and growth hormone. J. Clin. Endo- 
crinol. Metab. 81:3033-3038.

24. Macallan, D.C., M.A. McNurlan, E. Milne, A.G. Calder, P.J. Garlick, and G.E. Griffin. 1995. Whole body protein turnover from leucine kinetics and the response to nutrition in human immunodeficiency virus infection. Am. J. Clin. Nutr. 61:818-826.

25. McNurlan, M.A., P. Essén, A. Thorell, A.G. Calder, S.E. Anderson, O. Ljungqvist, A. Sandgren, I. Grant, I. Tjäder, J. Wernerman, and P.J. Garlick. 1994. Response of protein synthesis in human skeletal muscle to insulin: an investigation with L- $\left[{ }^{2} \mathrm{H}_{5}\right]$ phenylalanine. Am. J. Physiol. 267:E102-E108.

26. Calder, A.G., S.E. Anderson, I. Grant, M.A. McNurlan, and P.J. Garlick. 1992. The determination of low $\mathrm{d}_{5}$-phenylalanine enrichment $(0.002-0.09$ atom percent excess), after conversion to phenylethylamine, in relation to protein turnover studies by gas chromatography/mass spectrometry. Rapid Comm. Mass Spectrom. 6:421-424.

27. Frost, R.A., J. Fuhrer, R. Steigbigel, P. Mariuz, C.H. Lang, and M.C. Gelato. 1996. Wasting in the acquired immune deficiency syndrome is associated with multiple defects in the serum insulin-like growth factor system. Clin. Endocrinol. 44:501-514.

28. Olchovsky, D., M.C. Gelato, J.F. Bruno, J. Song, and M. Berelowitz. 1991. Pituitary IGF-I content and gene expression in the streptozotocin diabetic rat: evidence for tissue specific regulation. Endocrinology. 128:923-928.

29. Wassner, S.J., J.L. Schlitzer, and J.B. Li. 1980. A rapid, sensitive method for the determination of 3-methylhistidine levels in urine and plasma using highpressure liquid chromatography. Anal. Biochem. 104:284-289.

30. Clemmons, D.R., A. Smith-Banks, and L.E. Underwood. 1992. Reversal of diet-induced catabolism by infusion of recombinant insulin-like growth factor-I in humans. J. Clin. Endocrinol. Metab. 75:234-238.

31. Fong, Y., M. Rosenbaum, K.J. Tracey, G. Raman, D.G. Hesse, D.E. Matthews, R.L. Leibel, J.M. Gertner, D.A. Rischman, and S.F. Lowry. 1989. Recombinant growth hormone enhances muscle myosin heavy-chain mRNA accumulation and amino acid accrual in humans. Proc. Natl. Acad. Sci. USA. 86: $3371-3374$

32. Lundeberg, S., M. Belfrage, J. Wernerman, A. von der Decken, S. Thunell, and E. Vinnars. 1991. Growth hormone improves muscle protein metabolism and whole body nitrogen economy in man during a hyponitrogenous diet. Metabolism. 40:315-322.

33. Hammarqvist, F., C. Strömberg, A. von der Decken, E. Vinnars, and J. Wernerman. 1992. Biosynthetic human growth hormone preserves both muscle protein synthesis and the decrease in muscle-free glutamine, and improves whole-body nitrogen economy after operation. Ann. Surg. 216:184-191.

34. Wolf, R.F., D.B. Pearlstone, E. Newman, M.J. Heslin, A. Gonenne, M.E. Burt, and M.F. Brennan. 1992. Growth hormone and insulin reverse net whole body and skeletal muscle protein catabolism in cancer patients. Ann. Surg. 216:280-312.

35. Horber, F.F., and M.W. Haymond. 1990. Human growth hormone prevents the protein catabolic side effects of prednisone in humans. J. Clin. Invest. 86:265-272.

36. Mauras, N., and B. Beaufrere. 1995. Recombinant human insulin-like growth factor-I enhances whole body protein anabolism and significantly diminishes the protein catabolic effects of prednisone in humans without a diabetogenic effect. J. Clin. Endocrinol. Metab. 80:869-874.

37. Gore, D.C., D. Honeycutt, F. Jahoor, R.R. Wolfe, and D.N. Herndon. 1991. Effect of exogenous growth hormone on whole-body and isolated-limb protein kinetics in burned patients. Arch. Surg. 126:38-43.

38. Aukrust, P., N.-B. Liabakk, F. Müller, E. Lien, T. Espevik, and S.S. Frøland. 1994. Serum levels of tumor necrosis- $\alpha(\mathrm{TNF} \alpha)$ and soluble TNF receptors in human immunodeficiency virus type 1 infection-correlations to clinical immunologic, and virologic parameters. J. Infect. Dis. 169:420-424.

39. Kotler, D.P., and C. Grunfeld. 1995. Pathophysiology and treatment of the AIDS wasting syndrome. AIDS Clin. Rev. 229-275.

40. Pallarés-Trujillo, J., F.J. López-Soriano, and J.M. Argilés. 1995. TNF and AIDS: two sides of the same coin? Med. Res. Rev. 15:533-546.

41. Frost, R.A., C.H. Lang, and M.C. Gelato. 1997. Transient exposure of human myoblasts to tumor necrosis factor $\alpha$ inhibits serum and insulin-like growth factor-I stimulated protein synthesis. Endocrinology. In press.

42. Charters, Y., and R.F. Grimble. 1989. Effect of recombinant human tumor necrosis factor $\alpha$ on protein synthesis in liver, skeletal muscle and skin of rats. Biochem. J. 258:493-497.

43. Flores, E.A., B.R. Bistrian, J.J. Pomposelli, C.A. Dinarello, G.L. Blackburn, and N.W. Istfan. Infusion of tumor necrosis factor/cachectin promotes muscle catabolism in the rat. J. Clin. Invest. 83:1614-1622.

44. Espat, N.J., E.M. Copeland, and L.L. Moldawer. 1994. Tumor necrosis factor and cachexia: a current perspective. Surg. Oncology. 3:255-262.

45. Fryburg, D.A., R.A. Gelfand, and E.J. Barrett. 1991. Growth hormone acutely stimulates forearm muscle protein synthesis in normal humans. Am. $J$. Physiol. 260:E499-E504.

46. Fryburg, D.A., and E.J. Barrett. 1993. Growth hormone acutely stimulates skeletal muscle but not whole-body protein synthesis in humans. Metabolism. 42:1223-1227.

47. Fryburg, D.A. 1994. Insulin-like growth factor I exerts growth hormoneand insulin-like actions on human muscle protein metabolism. Am. J. Physiol. 267:E331-E336.

48. Rennie, M.J., K. Bennegård, E. Edén, P.W. Emery, and K. Lundholm. 1984. Urinary excretion and efflux from the leg of 3-methylhistidine before and after major surgical operation. Metabolism. 33:250-256.

49. Sjölin, J., H. Stjernström, S. Henneberg, E. Andersson, J. Mårtensson, G. Friman, and J. Larsson. 1989. Splanchnic and peripheral release of 3-methylhistidine in relation to its urinary excretion in human infection. Metabolism. 38: 23-29.

50. McNurlan, M.A., and P.J. Garlick. 1989. Influence of nutrient intake on protein turnover. Diabetes. Metab. Rev. 5:165-189.

51. Yarasheski, K.E., J.J. Azchweija, J.A. Campbell, and D.M. Bier. 1995 Effect of growth hormone and resistance exercise on muscle growth and strength in older men. Am. J. Physiol. 268:E268-E276.

52. Fryburg, D.A., R.J. Louard, K.E. Gerow, R.A. Gelfand, and E.J. Barrett. 1992. Growth hormone stimulates skeletal muscle protein synthesis and antagonizes insulin's antiproteolytic action in humans. Diabetes. 41:424-429.

53. Shambelan, M., K. Mulligan, C. Grunfeld, E.S. Daar, A. LaMarca, D.P. Kotler, J. Wang, S.A. Bozzette, and J.B. Breitmeyer. 1996. Recombinant human growth hormone in patients with HIV-associated wasting: a randomized, placebo-controlled trial. Ann. Intern. Med. 125:873-882.

54. Macallan, D.C., C. Noble, C. Baldwin, S.A. Jebb, A.M. Prentice, A Coward, M.B. Sawyer, T.J. McManus, and G.E. Griffin. 1995. Energy expenditure and wasting in human immunodeficiency virus infection. N. Engl. J. Med. 333:83-88.

55. Møller, J., J.O.L. Jørgensen, N. Møller, J.S. Christiansen, and J. Weeke. 1992. Effects of growth hormone administration on fuel oxidation and thyroid function in normal man. Metabolism. 41:728-731.

56. Møller, N., J.O.L. Jørgensen, P. Ovesen, O. Schmitz, K.G.M.M. Alberti, and J.S. Christiansen. 1993. Impact of 2 weeks high dose growth hormone treatment on basal and insulin stimulated substrate metabolism in human. Clin. Endocrinol. 39:577-581.

57. Froesch, E.R., P.D. Zenobi, and M. Hussain. 1994. Metabolic and therapeutic effects of insulin-like growth factor I. Horm. Res. (Basel.). 42:66-71. 